\title{
Streptomyces cellulolyticus sp. nov., a New Cellulolytic Member of the Genus Streptomyces
}

\author{
XIANZHEN LI* \\ Department of Food Technology, Dalian College of Light Industry, \\ Dalian 116001, People's Republic of China
}

\begin{abstract}
Actinomycete strain $L X^{T}$ ( $T=$ type strain), which decomposes cellulose, was identified as a member of the genus Streptomyces on the basis of morphological characteristics and the chemotype of the cell wall. The key characteristics of this organism are rectiflexibiles spore chains, a nonfragmenting vegetative mycelium, a warty spore surface, a type I cell wall, white to pink spore masses, and a lack of formation of soluble pigments (including melanin). These results indicate that strain $\mathrm{LX}^{\mathrm{T}}$ represents a distinct Streptomyces species, for which the name Streptomyces cellulolyticus is proposed. The type strain is strain LX, which has been deposited in the China General Microbiological Culture Collection Center as strain AS. 41332.
\end{abstract}

Cellulose, the major component of plant biomass, is a linear polymer of anhydroglucose units linked by $\beta$-1,4-glucoside bonds. Hydrogen binding with and between multiple layers of closely packed cellulose results in the formation of cellulose microfibrils. A variety of fungi and bacteria convert this insoluble substrate into soluble cellooligomers and ultimately to cellobiose and glucose.

Actinomycetes are widely distributed in soil, where they play an important role in the degradation of the lignocellulose of plant cell walls $(3,11)$. However, lignocellulose degradation in natural substrates is largely attributed to fungi, and the importance of actinomycetes in this process may be underestimated. Thus far, well-known cellulolytic actinomycetes include members of the genera Cellulomonas and Thermomonospora (2, 4, $7,9)$. In the genus Streptomyces, cellulose-degrading activity has been found in some strains $(6,10,17)$.

In a search of soil samples for cellulolytic bacteria, a streptomycete strain designated $\mathrm{LX}^{\mathrm{T}}(\mathrm{T}=$ type strain) was obtained, and this strain completely degraded filter paper, $\alpha$-cellulose, and Avicel in 2 or 3 days. In addition, almost no reducing sugar was detected during incubation of strain $\mathrm{LX}^{\mathrm{T}}$ in medium containing cellulose as the sole carbon source. In this paper, I present a morphological and physiological description of this strain. The data show that this isolate should be classified as a member of a new species of the genus Streptomyces, and the name Streptomyces cellulolyticus sp. nov. is proposed.

\section{MATERIALS AND METHODS}

Isolation. Soil samples to isolate organisms were obtained from the campus of Shandong University in Jinan, People's Republic of China. A 1-g (fresh weight) portion of a soil sample was suspended in $2 \mathrm{ml}$ of sterile distilled water, and aliquots of the resulting suspension were inoculated onto cellulose agar plates by directly plating 10 -fold serially diluted samples. After incubation for 3 days at $30^{\circ} \mathrm{C}$, several different types of colonies were observed on the plates. One colony of a strain that produced a large clearing zone, designated $\mathrm{LX}^{\mathrm{T}}$, was purified and subcultured on slants of cellobiose agar which contained nutrient salts medium supplemented with $0.2 \%$ (wt/vol) cellobiose and $0.1 \%$ (wt/vol) cellulose (Whatman CF11). Nutrient salts medium contained (per liter) $0.2 \mathrm{~g}$ of $\mathrm{MgSO}_{4} \cdot 7 \mathrm{H}_{2} \mathrm{O}$, $0.75 \mathrm{~g}$ of $\mathrm{KNO}_{3}, 0.5 \mathrm{~g}$ of $\mathrm{K}_{2} \mathrm{HPO}_{4}, 0.02 \mathrm{~g}$ of $\mathrm{FeSO}_{4} \cdot 7 \mathrm{H}_{2} \mathrm{O}, 0.04 \mathrm{~g}$ of $\mathrm{CaCl}_{2} \cdot 2 \mathrm{H}_{2} \mathrm{O}$, and $2 \mathrm{~g}$ of peptone. Cellulose agar plates were prepared by placing medium containing $4 \%$ Whatman $\mathrm{CF} 11$ and $1.5 \%(\mathrm{wt} / \mathrm{vol})$ agar over nutrient salts medium containing $1.5 \%$ (wt/vol) agar in plates.

Cultural and morphological characterization. A medium that contained $10 \mathrm{~g}$ of yeast extract per liter and $10 \mathrm{~g}$ of glucose per liter and was adjusted to $\mathrm{pH} 7.2$

* Mailing address: Department of Food Technology, Dalian College of Light Industry, 2 Baoding Street, Dalian 116001, People's Republic of China. Phone: 0411-2705580. (yeast extract-glucose medium) was used for general cultivation of actinomycete strains. The media used for morphological characterization of strain $\mathrm{LX}^{\mathrm{T}}$ were those described by Shirling and Gottlieb (15)

Cultural characteristics of cells in various media were recorded after incubation for 14 days at $30^{\circ} \mathrm{C}$ by the methods recommended by Shirling and Gottlieb (15). Morphological observations were made with a light microscope (model $\mathrm{CH}$; Olympus Optical Co., Ltd.) by using the method of Shirling and Gottlieb (15) The surfaces of spores and spore chains were examined by scanning electron microscopy with a JEOL model JEM 1200 electron microscope. The samples used for scanning electron microscopy were prepared by the method of Eguch et al. (5).

Physiological characteristics. Melanoid pigment production was examined on peptone-yeast extract-iron agar (ISP medium 6), on tyrosine agar (ISP medium 7), and in tryptone-yeast extract broth (ISP medium 1) (15).

Carbon utilization was determined on plates containing ISP basal medium 9 (15) to which filter-sterilized carbon sources were added to a final concentration of $1.0 \%$. The plates were incubated at $30^{\circ} \mathrm{C}$ and read after 14 days.

The ability of isolate $\mathrm{LX}^{\mathrm{T}}$ to utilize amino acids, including $\mathrm{L}$-asparagine, L-cysteine, L-threoine, L-glutamic acid, L-valine, L-arginine, and L-histidine (each at a concentration of $0.1 \%$ [wt/vol]), was determined in a basal medium containing $0.3 \%(\mathrm{wt} / \mathrm{vol})$ cellobiose, $0.05 \%(\mathrm{wt} / \mathrm{vol}) \mathrm{MgSO}_{4} \cdot 7 \mathrm{H}_{2} \mathrm{O}, 0.001 \%(\mathrm{wt} / \mathrm{vol})$ $\mathrm{FeSO}_{4} \cdot 7 \mathrm{H}_{2} \mathrm{O}, 0.1 \%$ (wt/vol) $\mathrm{K}_{2} \mathrm{HPO}_{4}$, and $1.2 \%$ (wt/vol) agar. Results were determined after 14 days.

The temperature range for growth was determined in nutrient salts medium containing $0.3 \%$ (wt/vol) cellobiose (nutrient salts-cellobiose medium) at tem peratures between 5 and $50^{\circ} \mathrm{C}$. The minimum $\mathrm{pH}$ that allowed growth was determined in nutrient salts-cellobiose medium by the method of Williams et al (18).

Sodium chloride tolerance was determined at concentrations of 1 to $12 \%$ in nutrient salts-cellobiose agar. Antibiotic susceptibility was determined with susceptibility disks (diameter, $8 \mathrm{~mm}$ ) consisting of filter paper saturated with an antibiotic solution; the antibiotics tested included dimethylchlortetracycline $(500$ $\mu \mathrm{g} / \mathrm{ml})$, vancomycin $(50 \mu \mathrm{g} / \mathrm{ml})$, kanamycin $(50 \mu \mathrm{g} / \mathrm{ml})$, rifampin $(50 \mu \mathrm{g} / \mathrm{ml})$, aminobenzylpenicillin $(50 \mu \mathrm{g} / \mathrm{ml})$, and penicillin $\mathrm{G}(10 \mathrm{IU} / \mathrm{ml})$. The disks were placed on the surfaces of nutrient salts-cellobiose medium plates seeded with a $2 \%$ vegetative inoculum.

Catalase activity was determined by bubble formation in a $3 \%$ hydrogen peroxide solution. Oxidase activity was determined by oxidation of $1 \%$ tetramethyl-p-phenylenediamine on filter paper. Nitrate reduction, indole production, hydrogen sulfide production, and hydrolysis of gelatin were studied as described by Lanyi (12). Other phenotypic characteristics were determined by the method described by Smibert and Krieg (16). All tests were performed a $30^{\circ} \mathrm{C}$

Cell wall analysis. The chemotypes of cell walls were determined as described previously (1). Whole-cell sugars were determined by the method of Nakagaito et al. (14)

\section{RESULTS}

Morphological characteristics. Strain $\mathrm{LX}^{\mathrm{T}}$ was an aerobic gram-positive bacterium which decomposed crystalline cellulose. This new isolate grew well on various organic media, but grew only moderately well on yeast extract-malt extract agar and did not grow on sucrose-nitrate agar or peptone-yeast extract-iron agar (Table 1). The reverse sides of colonies were 
TABLE 1. Cultural characteristics of strain $\mathrm{LX}^{\mathrm{T}}$

\begin{tabular}{lllc}
\hline \multicolumn{1}{c}{ Medium } & Amt of growth & & Color of: \\
\cline { 3 - 4 } & & Aerial mycelium & Vegetative mycelium \\
\hline Tryptone-yeast extract broth (ISP medium 1) & Abundant & White & Yellow \\
Yeast extract-malt extract agar (ISP medium 2) & Moderate & White & Yellow \\
Oatmeal agar (ISP medium 3) & Abundant & White, pink & Colorless \\
Inorganic salts-starch agar (ISP medium 4) & Abundant & Pink & Light yellow \\
Glyccrol-asparagine agar (ISP medium 5) & Abundant & Pink & Brown \\
Peptone-yeast extract-iron agar (ISP medium 6) & None & None \\
Tyrosine agar (ISP medium 7) & Abundant & White & None \\
Glucose-asparagine agar & Abundant & Pink & None \\
Yeast extract-glucose agar & Abundant & Light pink & Light yellow \\
Czapek's solution agar & Abundant & Pink & Yellow \\
Nutrient agar & Abundant & White & Brown \\
Sucrose-nitrate agar & None & None & Light yellow \\
\hline
\end{tabular}

yellow on several organic media but were brown on tyrosine agar, glycerol-asparagine agar, and Czapek's solution agar and were colorless on oatmeal agar. The aerial spore mass was white to pink. On all standard agar media, the aerial mycelium of strain $L X^{\mathrm{T}}$ formed straight to flexuous (rectiflexibiles) spore chains which consisted of 20 or more oval spores ( 2.1 to 2.3 by 2.5 to $2.7 \mu \mathrm{m}$ ) and did not form retinaculiaperti or spirales spore chains. The surfaces of the spores were warty (Fig. 1). The substrate mycelium was composed of long branching filaments that were 0.8 to $1.0 \mu \mathrm{m}$ in diameter. No fragmentation of the substrate mycelium was observed. No soluble pigments (including melanoid pigments) were formed.

Physiological characteristics. The physiological characteristics of strain $L X^{T}$ were as follows: oxidase activity and indole production were negative; catalase activity, acid reaction in milk, reduction of nitrate, and production of $\mathrm{H}_{2} \mathrm{~S}$ were positive; casein, cellulose, starch, and esculin were decomposed; gelatin was not liquefied; and no soluble pigments (including melanin) were formed.

Growth occurred in the presence of up to $10 \%$ sodium chloride. The optimum $\mathrm{pH}$ for growth was 7.2 , but growth occurred at $\mathrm{pH} 4$ to 10 . The temperature range at which growth occurred was 10 to $40^{\circ} \mathrm{C}$, and optimum growth occurred at $30^{\circ} \mathrm{C}$. Strain $\mathrm{LX}^{\mathrm{T}}$ used D-glucose, D-fructose, L-arabinose, sucrose, D-xylose, raffinose, and i-inositol, but not L-rhamnose,

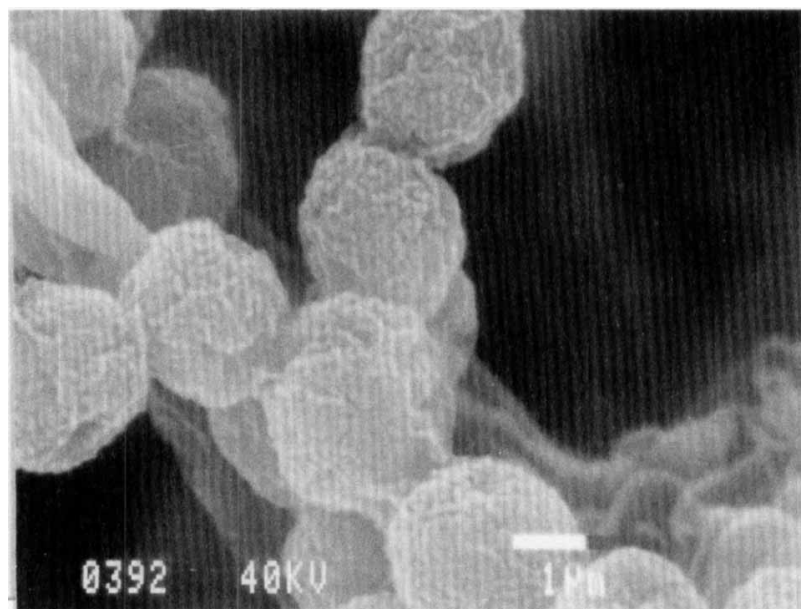

FIG. 1. Scanning electron micrograph showing the warty surfaces of spores of strain $\mathrm{LX}^{\mathrm{T}}\left(=\mathrm{AS} .41332^{\mathrm{T}}\right)$. The organism was grown on yeast extract-glucose agar at $30^{\circ} \mathrm{C}$ for 14 days. as the sole carbon source. Tests for utilization of amino acids showed that asparagine, L-cysteine, and L-threonine served as nitrogen sources. Strain $\mathbf{L X}^{\mathrm{T}}$ was resistant to dimethylchlortetracycline, vancomycin, kanamycin, rifampin, and aminobenzylpenicillin and was susceptible to penicillin $G$.

Analysis of cell wall hydrolysates of strain $\mathrm{LX}^{\mathrm{T}}$ revealed that the cell walls contained LL-diaminopimelic acid and glycine, but no characteristic sugars were found. This information indicates that the cell wall type is type I and that the sugar pattern type is type $C(8)$.

\section{DISCUSSION}

The morphological and cultural characteristics, as well as the cell wall and sugar pattern types, provide evidence that strain $\mathrm{LX}^{\mathrm{T}}$ should be assigned to the genus Streptomyces.

A comparison of isolate $\mathrm{LX}^{\mathrm{T}}$ with the previously described Streptomyces species (13) showed that only one of the previously described species has rectiflexibiles spore chain morphology and warty spore surfaces; this species, Streptomyces lomondensis, produces a melanoid pigment. In addition, $S$. lomondensis, but not isolate $\mathrm{LX}^{\mathrm{T}}$, also forms retinaceliapti or spirales spore chains. The spore mass of isolate $\mathrm{LX}^{\mathrm{T}}$ is white to pink, while the $S$. lomondensis spore mass is blue. Casein is degraded by isolate $\mathrm{LX}^{\mathrm{T}}$, but not by $S$. lomondensis. Isolate $\mathrm{LX}^{\mathrm{T}}$ was similar to Streptomyces hygroscopicus and Streptomyces cellulosae in some physiological and cultural test reactions; however, isolate $\mathrm{LX}^{\mathrm{T}}$ could be separated from these species on the basis of spore chain form, spore surface type, and spore mass color. I believe that strain $\mathrm{L} X^{\mathrm{T}}$ represents a new species of the genus Streptomyces. Thus, I propose the name Streptomyces cellulolyticus for strain $\mathrm{LX}^{\mathrm{T}}$. A description of this new species is given below.

Description of Streptomyces cellulolyticus sp. nov. Streptomyces cellulolyticus (cel.lu.lo.ly'ti.cus. M. L. n. cellulosum, cellulose; Gr. adj. lyticus, dissolving; M. L. adj. cellulolyticus, decomposing cellulose).

Spore chains are rectiflexibiles, with 20 or more spores per chain. The spores are oval and are 2.1 to 2.3 by 2.5 to $2.7 \mu \mathrm{m}$. The spore surface is warty. Mycelia do not fragment into coccoid or bacillary structures. The branching substrate mycelium is yellow on yeast extract-malt extract agar, inorganic saltsstarch agar, glucose-asparagine agar, and nutrient agar; brown on glycerol-asparagine agar, tyrosine agar, and Czapek's solution agar; and colorless on oatmeal agar. The aerial spore mass is white to pink.

Soluble pigments, including melanin, are not produced. The organism is positive for catalase activity and production of $\mathrm{H}_{2} \mathrm{~S}$ 
and negative for oxidase activity and indole production. Nitrate is reduced. Starch, casein, and esculin are hydrolyzed. Gelatin is not liquefied. Cellulose is decomposed. D-Glucose, D-fructose, L-arabinose, sucrose, D-xylose, raffinose, and i-inositol are utilized for growth, but L-rhamnose is not utilized. L-Asparagine, L-cystine, and L-threonine can be used as nitrogen

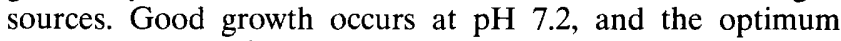
temperature is $30^{\circ} \mathrm{C}$. Growth occurs in the presence of up to $10 \% \mathrm{NaCl}$. Isolate $\mathrm{LX}^{\mathrm{T}}$ is susceptible to penicillin $\mathrm{G}$, but not to dimethylchlortetracycline, vancomycin, kanamycin, rifampin, and aminobenzylpenicillin. The cell wall chemotype is chemotype I, and the cell wall contains LL-diaminopimelic acid and glycine; no characteristic sugars are detected as whole-cell sugars.

The type strain is strain LX, which has been deposited in the China General Microbiological Culture Collection Center as strain AS. 41332.

\section{ACKNOWLEDGMENT}

I thank the National Natural Science Foundation of China for partial financial assistance.

\section{REFERENCES}

1. Becker, B., M. Lechevalier, and H. A. Lechevalier. 1965. Chemical composition of cell-wall preparations from strains of various form-genera of aerobic actinomycetes. Appl. Microbiol. 13:236-248.

2. Calza, R. E., D. C. Irwin, and D. B. Wilson. 1985. Purification and characterization of two $\beta-1,4$-endogulcanases from Thermomonospora fusca. Biochemistry 24:7797-7804.

3. Crawford, D. L. 1986. The role of actinomycetes in the decomposition of lignocellulose. FEMS Symp. 34:715-728.

4. Dermoun, Z., and J. P. Belaich. 1988. Crystalline index change in cellulose during aerobic and anaerobic Cellulomonas uda growth. Appl. Microbiol. Biotechnol. 27:399-404.
5. Eguchi, T., N. Takada, S. Nakamura, T. Tanaka, T. Makino, and Y. Oshima 1993. Streptomyces bungoensis sp. nov. Int. J. Syst. Bacteriol. 43:794-798

6. Enger, M. D., and B. P. Sleeper. 1965. Multiple cellulase system from Streptomyces antibioticus. J. Bacteriol: 89:23-27.

7. Fennington, G., D. Neubauer, and F. Stutzenberger. 1983. Adenosine $3^{\prime}, 5^{\prime}$ cyclic monophosphate levels in Thermononospora curvata during cellulase biosynthesis. Biotechnol. Bioeng. 25:2271-2276.

8. Gottlieb, D. 1974. Order I. Actinomycetales Buchanan 1917, 162, p. 657-659. In R. E. Buchanan and N. E. Gibbons (ed.), Bergey's manual of determinative bacteriology, 8th ed. The Williams and Wilkins Co., Baltimore, Md.

9. Kim, B. H., and J. W. T. Wimpenny. 1981. Growth and cellulolytic activity of Cellulomonas flavigena. Can. J. Microbiol. 27:1260-1266.

10. Kluepfel, D., F. Shareck, F. Mondou, and R. Morosoli. 1986. Characterization of cellulase and xylase activities of Streptomyces lividans. Appl. Microbiol. Biotechnol. 2:230-234.

11. Lacey, J. 1973. Actinomycetes in soils, composts and fodders, p. 231-251. In G. Sykes and E. A. Skinner (ed.), Actinomycetes: characteristics and practical importance. Academic Press, London, United Kingdom.

12. Lanyi, B. 1987. Classical and rapid identification methods for medically important bacteria. Methods Microbiol. 19:1-67.

13. Locci, R. 1989. Streptomyces and related genera, p. 2451-2506. In S. T. Williams, M. E. Sharpe, and J. G. Holt (ed.), Bergey's manual of systematic bacteriology, vol. 4. The Williams \& Wilkins Co., Baltimore, Md.

14. Nakagaito, Y., A. Yokota, and T. Hasegawa. 1992. Three new species of the genus Streptomyces: Streptomyces cochleatus sp. nov., Streptomyces parecochleatus sp. nov. and Streptomyces azaticus sp. nov. J. Gen. Appl. Microbiol. 38:105-120.

15. Shirling, E. B., and D. Gottlieb. 1966. Methods for characterization of Streptomyces species. Int. Syst. Bacteriol. 16:313-340

16. Smibert, R. M., and N. R. Krieg. 1981. General characterization, p. 409-443. In P. Gerhardt, R. G. E. Murray, R. N. Costilow, E. W. Nester, W. A. Wood, N. R. Krieg, and G. B. Phillips (ed.), Manual of methods for general bacteriology. American Society for Microbiology, Washington, D.C.

17. Spear, L., J. Gaallagher, L. McHale, and A. P. McHale. 1993. Production of cellulase and $\beta$-glucosidase activities following growth of Streptomyces hygroscopicus on cellulose containing media. Biotechnol. Lett. 15:1265-1268

18. Williams, S. T., F. L. Davies, C. I. Mayfield, and M. R. Khan. 1971. Studies on the ecology of actinomycetes in soil. II. The $\mathrm{pH}$ requirements of streptomycetes from two acid soils. Soil Biol. Biochem. 3:187-195. 